\title{
EXTENSIONAL FLOW BEHAVIOR OF POLYMER SOLUTIONS AND PARTICLE SUSPENSIONS IN A SPINNING MOTION
}

\author{
C. B. WeInBERGer $\dagger$ and J. D. Goddard \\ University of Michigan, Department of Chemical Engineering, Ann Arbor, MI 48104, U.S.A.
}

(Received 14 August 1973; in revised form 22 June 1973)

\begin{abstract}
Mechanical spinning of fluid filaments was used to generate an extensional flow, in which rheological measurements were obtained for a Newtonian fluid, two aqueous polymer solutions, and two fluid suspensions of rod-shaped particles. The tensile stress was determined by measuring the tensile force of the fluid filament while the kinematics were determined from photographic measurement of the filament profile and the assumption of a flat velocity profile. The measured tensile stresses for the Newtonian fluid matched predicted stresses, thereby confirming the validity of the experimental technique.

The spinning behavior of each polymer solution could be correlated as stress versus extension rate. The apparent "spinning viscosity" increased with increasing rate of extension, in contrast to shear-thinning behavior in viscometric flow. For the fluid suspensions, the presence of rod-shaped particles increased the apparent viscosity far more in extensional flow than in shear. Tensile stresses calculated from a theoretical formula for suspensions proposed by Batchelor agreed rather well with experiment. Some general criteria for the interpretation of the spinning experiment are proposed, and some microrheological implications of the present findings are discussed.
\end{abstract}

\section{INTRODUCTION}

The importance of the so-called extensional flows to the rheology of non-Newtonian fluids has been discussed frequently in recent literature (Ziabicki 1967; Dealy 1971; Cogswell 1972). On the one hand, there is considerable motivation for practical rheological tests based on such flows, insofar as they occur in industrial processing operations such as fiber spinning and film forming.

On the other hand, there is good reason to believe that measurements of fluid behavior in such flows is highly relevant to theoretical rheology, not only as a guide for formulating constitutive equations, but also as a means of elucidating the microrheology of fluids.

In the language of continuum mechanics, a history of extensional motion at a material point is characterized at any time $t$ by a rate of deformation tensor which, for all past times $t^{\prime}<t$, is given by

$$
\mathbf{E}\left(t^{\prime}\right)=\dot{\varepsilon}_{1}\left(t^{\prime}\right) \mathbf{e}_{1} \mathbf{e}_{1}+\dot{\varepsilon}_{2}\left(t^{\prime}\right) \mathbf{e}_{2} \mathbf{e}_{2}+\dot{\varepsilon}_{3}\left(t^{\prime}\right) \mathbf{e}_{3} \mathbf{e}_{3}
$$

relative to an appropriate orthonormal basis $\mathbf{e}_{1}(i=1,2,3)$ fixed in the material. The $\dot{\varepsilon}_{i}(i=1,2,3)$ denote the principal rates of deformation, and whenever they are independent of the time $t^{\prime}$ the motion is designated as steady extensional. Of course, for incompressible

$\dagger$ Present address: Drexel University, Department of Chemical Engineering, Philadelphia, PA 19104, U.S.A. 
fluids, or for isochoric motions, only two of the three $\dot{\varepsilon}_{i}$ are independent, since

$$
\dot{\varepsilon}_{1}+\dot{\varepsilon}_{2}+\dot{\varepsilon}_{3}=0
$$

A further special case of particular interest here is that of "simple" or "uniaxial" extension, defined by

$$
\dot{\varepsilon}_{2}=\dot{\varepsilon}_{3}=-\dot{\varepsilon}_{1} / 2, \quad \dot{\varepsilon}_{1}=\dot{\varepsilon}\left(t^{\prime}\right) \geq 0
$$

for which we may, without ambiguity, designate $\dot{\varepsilon}$ as the "extension rate". $\dagger$

As a further point of interest, we recall that steady extensional motions always give rise to an exponentially large elongation of certain lineal fluid elements as $t^{\prime} \rightarrow-\infty$. It is this kinematical property which characterizes a subset of the so-called "motions of constant stretch history" (Truesdell 1966). It also accounts for the mathematical predictions of an extensional "catastrophe", by numerous phenomenological models for viscoelastic fluids, wherein there exist singularities of infinite stress at finite levels of the extension rates.

As for the plausibility of such a phenomenon in real fluids, we tend to share the view of Tanner (1968) and believe that such predictions should be regarded as mathematical artifacts, which reflect limitations on the fluid models in question. It is recognized that predictions of large but finite tensile stresses in extension may be qualitatively correct for many non-Newtonian fluids, and this appears to have been confirmed by the work to be presented here and previously by certain other experimental studies (Metzner \& Metzner 1970). Moreover, the occurrence of large stresses is plausible when viewed from the standpoint of molecular- or microrheology, because the characteristic absence of vorticity, in steady or quasi-steady extensional motion, together with the exponential stretching of fluid elements, provides in principle an effective mechanism for order or alignment of fluid microstructure. This is especially likely in solutions or suspensions, respectively, of extensible or elongated macro-molecules or of particles in viscous fluids, as is suggested by the classical hydrodynamic theories for the motion of deformable or elongated bodies suspended in a Newtonian fluid.

Recent improvements in slender body theory for the Stokes-flow regime, and the resultant calculations for suspensions of rigid rod-like particles (Batchelor 1971), yield predictions of extremely large stresses in simple extension.

These considerations provide much of the motivation for the present experimental work, whose original purpose was two-fold:

(a) to develop further a rheological test for studying the mechanical behavior of liquid filaments subjected to simple extension;

(b) to make measurements on high molecular weight polymer solutions as well as on suspensions of rod-like particles in a Newtonian fluid, a system for which some theoretical models are available.

Since we were particularly interested in measurements that would be applicable to

\footnotetext{
+ It is desirable to distinguish between the cases $\dot{\varepsilon}_{1}>0$ and $\dot{\varepsilon}_{1}<0$, the latter being more appropriately termed "uniaxial compression", a special, axially symmetric form of "biaxial extension" $\left(\dot{\varepsilon}_{1}<0, \dot{\varepsilon}_{2}>0, \dot{\varepsilon}_{3}>0\right)$.
} 
liquids of moderate shear viscosity, the kind of tensile tests appropriate to solids and highly viscous liquids, such as that used by Trouton (1906) in his classic experiments, and later variants due to Cogswell (1972) and Meissner (1972), were not practicable. Hence, some modification of the spinning technique used for formation of synthetic fibers quite naturally suggested itself.

At the inception of the present work, the only reported measurement of this type on polymer solutions appeared to be that of Nitschmann \& Schrade (1948), who did not, however, make sufficiently detailed or precise measurements to permit estimation of local stress and extension rate at various points along a liquid filament. During the course of our work, a report by Zidan (1969) on similar measurements appeared and this work is discussed below. Since then, several other measurements of this same type have been reported for polymer melts, but these will not be discussed in detail here.

\section{PRINCIPLES FOR INTERPRETATION OF THE MEASUREMENT}

There have been several analyses given of the mechanics of isothermal filament spinning for various kinds of fluids (Clarke 1968; Matovich \& Pearson 1969; Slattery 1966). In the interest of clarifying certain fundamental questions relating to the interpretation of data, it seems worthwhile to recall the basic notions underlying our treatment of filament rheology and dynamics.

\subsection{Rheological aspects}

We make the usual constitutive assumptions for an isotropic incompressible fluid, e.g. of the type defined by Noll's (1958) simple-fluid theory. Then the instantaneous stress at a fluid particle subjected to the simple extension of [1.1] has the form (Weinberger 1970),

$$
\mathbf{S}(t)=\frac{2}{3} \tau(t) \mathbf{e}_{1} \mathbf{e}_{1}-\frac{1}{3} \tau(t)\left(\mathbf{e}_{2} \mathbf{e}_{2}+\mathbf{e}_{3} \mathbf{e}_{3}\right)-p \mathbf{I}
$$

where $p$ is a rheologically indeterminate pressure, and

$$
\left.\tau(t)=S_{11}(t)-S_{22}(t) \equiv S_{11}(t)-S_{33}(t)=t\left[\begin{array}{c}
\dot{\varepsilon} \\
t^{\prime} \\
-\infty
\end{array}\right)\right]
$$

the (axial-radial) principal stress difference, is a functional on the extension rate $\dot{\varepsilon}\left(t^{\prime}\right)$. For steady extension (Coleman \& Noll 1962), [2.2] reduces to a (steady, material) function of $\dot{\varepsilon}$.

$$
\tau=\tau_{T}(\dot{\varepsilon})=\eta_{T}(\dot{\varepsilon}) \dot{\varepsilon}
$$

say where $\eta_{T}(\dot{\varepsilon})$ is the so-called "Trouton" or tensile viscosity.

For fluids with "fading" memory (Coleman \& Noll 1961, 1962), one has in the Newtonian limit, $\dot{\varepsilon} \rightarrow 0$, that $\eta_{T} \rightarrow 3 \mu$, where $\mu$ is the (Newtonian limit of the) shear viscosity. For general fluids of this type, however, $\eta_{T}$ is not otherwise simply related to the viscometric material functions.

For an unsteady extension, characteristic of a spinning filament, one does not in general expect a relation of the form [2.3] to exist between the instantaneous values of extension 
rate $\dot{\varepsilon}(t)$ and the stress $\tau(t)$. Indeed, such a relation would be expected to obtain only in the following special motions:

(I) for all quasi-steady extensions (retarded motions), corresponding to the limit of small values of some characteristic time ratio (or Deborah number), based on the strain acceleration and a relaxation time for the fluid; or

(II) for a monogenic family of extensions, i.e. extensions all having essentially the same history.

These ideas can be illustrated, as in figure 1, by a phase-plane representation of a dimensionless extension rate

$$
\alpha=i_{0} \dot{\varepsilon} \quad(>0)
$$

versus the magnitude of a dimensionless strain acceleration (or Deborah number squared),

$$
\frac{\mathrm{d} \alpha}{\mathrm{d} \theta}=\lambda_{0}^{2} \ddot{\varepsilon}
$$

where

$$
\ddot{\varepsilon}=\mathrm{d} \dot{\varepsilon} / \mathrm{d} t, \quad \theta=t / \lambda_{0},
$$

and $\lambda_{0}$ is a characteristic relaxation time for the fluid. The plot is essentially then a flowdiagnostic diagram of the type proposed by Pipkin (1972).

Extensions of type (I) may be thought of as being all those curves of $\alpha$ vs $d \alpha / \mathrm{d} \theta$ that lie in a region $|\mathrm{d} \alpha / \mathrm{d} \theta| \ll 1$ near the $\alpha$-axis. In contrast, a monogenic family of extensions is represented by a single curve, e.g. (II) on the diagram, to which has been attributed the

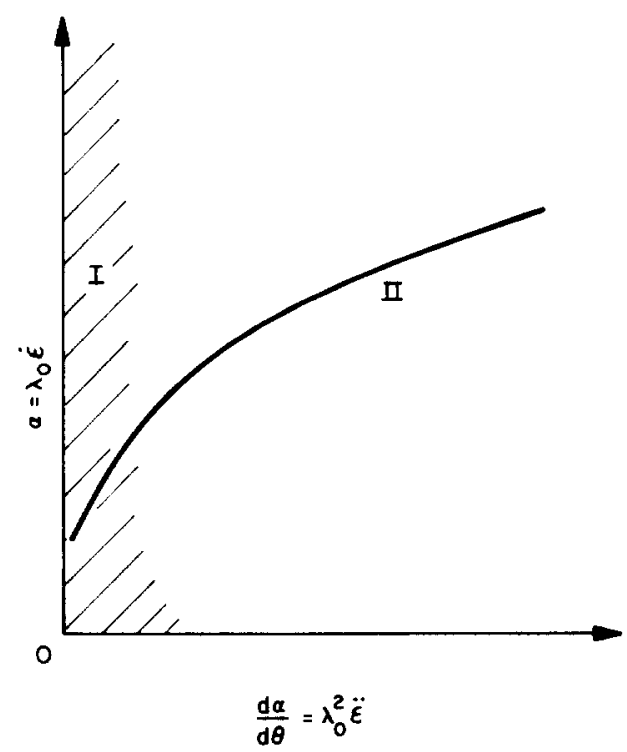

Figure 1. "Flow-diagnostic", phase-plane representation for (isothermal) spinning. I-Region of quasi-steady extension. II-Monogenic family of spinning motions, all having the same history of extension rate. 
general shape one might expect for a spinning process. Thus, in terms of the original variables $\ddot{\varepsilon}$, $\dot{\varepsilon}$, a sufficiently smooth monogenic family of extensions is represented by the second-order differential equation

$$
\ddot{\varepsilon}=G(\dot{\varepsilon})
$$

where a given function $G$ is the generator of the family. $\dagger$ It is well-known that the general solution of [2.6] can be represented by a mapping of $\dot{\varepsilon}(t)$ into $\dot{\varepsilon}\left(t^{\prime}\right)$ as

$$
\dot{\varepsilon}\left(t^{\prime}\right)=H\left[t^{\prime}-t, \dot{\varepsilon}(t)\right]
$$

where the function $H$ is uniquely determined by the generator $G$ and $t, t^{\prime}$ are arbitrary times.

One of the major factors determining the suitability of the spinning experiment as a rheological test is the reproducibility or controllability of the kinematics. (Generally, one demands of any rheological test that the history of deformation be both measurable and easily parameterized, the latter of which, in its simplest interpretation, implies that time can be eliminated from the description of the experiment.)

An important question, therefore, is whether the motion in a set of spinning experiments with a given fluid falls into category (I) or (II) above. In case (I), quasi-steady motion, one obtains the relation [2.3]; i.e. the stress is determined by the steady-state material function.

In case (II), it follows from [2.2], [2.6] and [2.7] that the instantaneous stress is given formally by

$$
\tau(t)=\tau_{G}[\dot{\varepsilon}(t)]
$$

In this restricted sense, $\tau_{G}$ is a valid material property, determined by the form of $G$ in [2.6], but not generally identical with the steady-stress function $\tau_{T}$ of [2.3].

The experimental results to be presented later show that for the fluids and conditions studied here, the spinning motion appears to represent a particularly reproducible history, insofar as it is possible to correlate instantaneous stress and extension rate for different spinning conditions.

\subsection{Kinematical and dynamical aspects}

In a spinning motion forces from gravity, inertia and surface tension contribute to the tensile stress. To distinguish the material's rheological response to the extension rate, it is necessary to separate the effects of these forces.

On account of the free-surface boundary conditions, application of the full equations of motion yields complex equations, requiring difficult techniques (Clarke 1968; Matovich $\&$ Pearson 1969) to achieve even approximate solutions. However, the dynamical equations simplify considerably whenever the radial variations in axial velocity and tensile stress can be neglected, which requires the assumption of a flat velocity profile, hence, a radially homogeneous extension. This procedure, as employed by G. I. Taylor (Brown 1961) for a falling sheet of fluid, can be justified to some extent as an approximation corresponding to the first-order term in a perturbation series of the type proposed by Matovich $\&$ Pearson (1969).

$\uparrow$ This is a generalization of an idea discussed by Kanel (1970), cf. the Acknowledgement. 
The resulting steady-state axial momentum balance and continuity equation combine to yield the equations for axial velocity $u(x)$ and extension rate:

$$
u \frac{\mathrm{d}}{\mathrm{d} x}(\tau / u)=-\rho g+\rho\left[u+\frac{\sigma}{2 \rho} /\left(\frac{\pi}{Q u}\right)\right] \frac{\mathrm{d} u}{\mathrm{~d} x}
$$

with

$$
\dot{\varepsilon}(t)=\mathrm{d} u / \mathrm{d} x(x), \mathrm{d} t=\mathrm{d} x / u, \quad \text { and } \quad \mathrm{d} / \mathrm{d} t=u(\mathrm{~d} / \mathrm{d} x) .
$$

Here gravity, acceleration and surface tension $\sigma$ are included but both inertial and drag forces from the surrounding medium are neglected. $\dagger$

In the present work we shall employ the direct numerical quadrature of [2.9] to deduce the stress $\tau$ from observations of the filament diameter by means of the integral

$$
\tau=c u+\rho u \int_{0}^{x}\left\{-g+\left[u+\frac{\sigma}{2 \rho} \int\left(\frac{\pi}{Q u}\right)\right] \frac{\mathrm{d} u}{\mathrm{~d} x}\right\} \frac{\mathrm{d} x}{u}
$$

where, in terms of filament radius $R(x)$ and volumetric efflux, $Q$.

$$
u=Q / \pi R^{2}(x), \text { and where } c=\tau_{0} / u_{0}=F_{0} / Q \text {, a constant }
$$

is the stress/velocity or force/efflux ratio, at some reference point $x=0$ on the filament. However, it is worth commenting briefly on [2.9], viewed as differential equation for predicting $u(x)$ for a given fluid.

Clarke (1968) has solved this equation analytically for the special case of a Newtonian fluid with negligible surface tension. For highly viscous Newtonian fluids, where surface tension, gravity and inertia can all be neglected, one has constant-force spinning with

$$
\tau=c u, \quad F(x) / Q=F_{0} / Q=c,
$$

and the solution of [2.9] yields for the velocity $u(x)$ a simple exponential function of position.

The theoretical problem of solving [2.9], subject to the appropriate end or boundary conditions, has been discussed by Slattery (1966); Ziabicki (1967); Matovich \& Pearson (1969). The effect of die or eductor prehistory is especially important in this context. Of course, for an arbitrary fluid model, with general rheology of the form [2.2], nothing very definite can be said without imposing certain special assumptions on the class of kinematics (Slattery 1966). Ultimately, however, one must verify some reasonable degree of compatibility with the dynamics, as described e.g. by [2.9] and with real end conditions.

In this regard, the special case of constant-force spinning, [2.12] is practically and theoretically important. Here, by means of [2.9] and [2.12], one finds that

$$
\dot{\tau}=\mathrm{d} \tau / \mathrm{d} t=\tau \dot{\varepsilon}
$$

which is equivalent to

$$
\tau(t)=\tau(s) \exp \left[\int_{s}^{t} \dot{\varepsilon}\left(s^{\prime}\right) \mathrm{d} s^{\prime}\right], \quad \text { or } \quad \tau(t)=\tau(s) A(s) / A(t),
$$

\footnotetext{
† The corresponding equation, [3.56] of Weinberger (1970), shows an erroneous factor of 4 in the surfacetension term.
} 
where $t$ and $s$ are arbitrary values of the time variable and $A(t)$ denotes (local) cross-sectional area of the filament.

The relations [2.13] or [2.14] can be regarded as general integrals or invariants of this particular spinning motion, either of which, together with the constitutive relation [2.2] and an appropriate end condition, provides the full equations of motion governing the filament behavior.

Thus, in the case (I) of Section 2.1, quasi-steady motions where [2.3] holds, one obtains the governing differential equation, in an implicit form, as

$$
\tau=\tau_{T}(\dot{\tau} / \tau)
$$

If the motion cannot be considered as quasi-steady, one obtains instead a functional relation from [2.13] and [2.2] whose form indicates that, for a given material (or constitutive functional), all constant-force spinning experiments are members of the same monogenic family of extensions. The equation of motion reduces then to the analog of [2.15],

$$
\tau=\tau_{G}(\dot{\tau} / \tau)
$$

and, incidentally, the generator $G$ of [2.6] is determined by the functional relation

$$
G(\dot{\varepsilon})=\frac{\dot{\varepsilon} \tau_{G}(\dot{\varepsilon})}{\mathrm{d} \tau_{G}(\dot{\varepsilon}) / \mathrm{d} \dot{\varepsilon}} .
$$

Of course, the latter cannot be made more definite without a specific constitutive equation.

The above result can perhaps be clarified by considering a specific constitutive model, in the form of a generalized Maxwell-Oldroyd fluid (cf. Zidan 1969), reduced to a form appropriate to simple extension, say

$$
\tau+\lambda \dot{\tau}=\tau_{T}(\dot{\varepsilon})=\eta_{T} \dot{\varepsilon}
$$

where the relaxation time $\lambda$ and the Trouton viscosity $\eta_{T}$ are assumed to depend on extension rate $\dot{\varepsilon}$. It follows from [2.13] and [2.18] that for all constant-force spinning motions

$$
\tau=\tau_{G}(\dot{\varepsilon})=\tau_{T}(\dot{\varepsilon}) /[1+\lambda(\dot{\varepsilon}) \dot{\varepsilon}]
$$

or for $\dot{\varepsilon}>0$,

$$
\eta_{\text {spin }} \stackrel{\text { def }}{=} \frac{\tau_{G}}{\dot{\varepsilon}}=\frac{\eta_{T}(\dot{\varepsilon})}{1+\lambda(\dot{\varepsilon}) \dot{\varepsilon}}
$$

where $\eta_{\text {spin }}$ is an (apparent) spinning viscosity $\dagger$

The example just considered illustrates the general point that for constant-force spinning one can correlate instantaneous (or local) stress and extension rate along the filament but, at the same time, cannot distinguish between quasi-steady and unsteady (i.e. purely viscous and elasticoviscous) behavior. Also, one can say that the stress or the spinning viscosity will be less than the steady stress or Trouton viscosity, for a fluid whose behavior

† There is, of course, some license taken here in using the term viscosity to describe a stress which involves elastic as well as viscous or dissipational response. 
is approximated by [2.18] with $\lambda>0$. We suspect that this result might also hold for a much wider class of fluid models.

The interesting general questions remain as to whether there exists any wider class of spinning motions for which instantaneous stress and extension rate can be correlated and, if so, what relation exists between spinning viscosity and Trouton viscosity.

The foregoing considerations are thought to be crucial to the interpretation of the spinning experiment, where material rheology and dynamics interact to determine the type of rheological test one obtains for a given material. Such a test, therefore, may not be kinematically reproducible for different materials, or even for a given material with different spinning conditions.

These questions will be reconsidered below, as they pertain to the experiments of the present study.

\section{EXPERIMENTAL METHOD AND FLUID CHARACTERIZATION}

\subsection{Fluids employed}

The test fluids consisted of two aqueous polymer solutions, one silicone oil, and two fluid suspensions. The polymer solutions exhibited marked elastic and shear-thinning behavior and the silicone oil appeared Newtonian. The fluid suspensions contained short lengths of fiber-glass suspended in Newtonian fluids.

The first polymer solution, containing 1.5 weight-per cent Separan AP30† dissolved in a $1: 1$ (by weight) glycerol-water solvent, was chosen for several reasons. Its behavior under dynamic and steady shearing conditions had been studied previously (Huppler, Ashare \& Holmes 1967) and, in addition to possessing the desired order-of-magnitude zero-shear viscosity of $3000 \mathrm{P}$, it exhibited the usual shear-thinning and gradual stressrelaxation effects. The second polymer solution was prepared by dissolving 3.03 weightper cent Polyox WSR-301 $\ddagger$ in a solvent composed of $1: 2$ glycerol-water plus 11 per cent isopropanol. (Isopropanol is added to enhance the stability of the Polyox solution by retarding the auto-oxidation of the polyethylene oxide.) The Polyox solution also exhibited shear-thinning and gradual stress-relaxation effects but possessed a zero-shear viscosity five times that of the Separan. (We recall that the purpose of the glycerol as an aqueous polymer-solution additive is to increase the viscosity of the solvent and thereby to enhance the elastic properties of the solutions.)

The silicone oil is Dow Corning 210 fluid $\S$ whose shear viscosity, determined with a falling-ball viscometer, is $1025 \mathrm{P}$. The Newtonian fluids used in the fluid suspensions were the same silicone oil mentioned above and Indopol $\|$, with a shear, viscosity of $205 \mathrm{P}$. The suspended particles of fiber-glass measured $3.5 \mu \mathrm{M}$ in diameter by $200 \mu \mathrm{M}$ long; both suspensions contained 1.3 volumetric-per cent particles.

\footnotetext{
† A polyacrylamide. MW 2-3 million, made by Dow Chemical Co. † A polyethylene oxide MW 4,000,000. made by Union Carbide Co. $\$$ A dimethylpolysiloxane made by Dow Corning Co $\|$ A polybutene, MW 750, made by American Oil Co.
} 
Shear properties of the polymer solutions were measured with a Weissenberg rheogoniometer, Model R-16. These properties included apparent shear viscosity and stress relaxation upon cessation of shear, the gradual stress decay was used as an approximate measure of relaxation time. The shear viscosities of the fluid suspensions were measured with a Brookfield viscometer.

\subsection{Extensional-flow apparatus and tests}

With the extensional-flow apparatus, a spinning motion was obtained by extruding the test fluid through a circular nozzle and continuously winding up the fluid filament tangentially onto a rotating disk (figure 2). The disks used were $3.2 \mathrm{~mm}$ thick and either 38.1 or $50.8 \mathrm{~mm}$ in diameter. Rotation speeds ranged from 15 to $72 \mathrm{rev} / \mathrm{min}$. The fluid, apparently held to the disk by surface tension, was scraped off with a doctor blade positioned half a revolution around from the contact point. The nozzle was mounted on a torsion bar so that the deflection of the nozzle tip, detected with a position transducer, provided a direct measure of the tensile force in the filament near the nozzle. The tip of the nozzle was approximately $120 \mathrm{~mm}$ from the torsion bar. A deflection of $10^{-2} \mathrm{~mm}$ corresponded to a typical force of $940 \mathrm{dyn}$. The precision of the force measurement was approximately 5 per cent. A syringe pump delivered the fluid at a constant flow rate of 24.7 or $74.4 \mathrm{~mm}^{3} / \mathrm{sec}$. Three different nozzle diameters, $1.6,2.5$ and $3.6 \mathrm{~mm}$, respectively, were tried, in an attempt

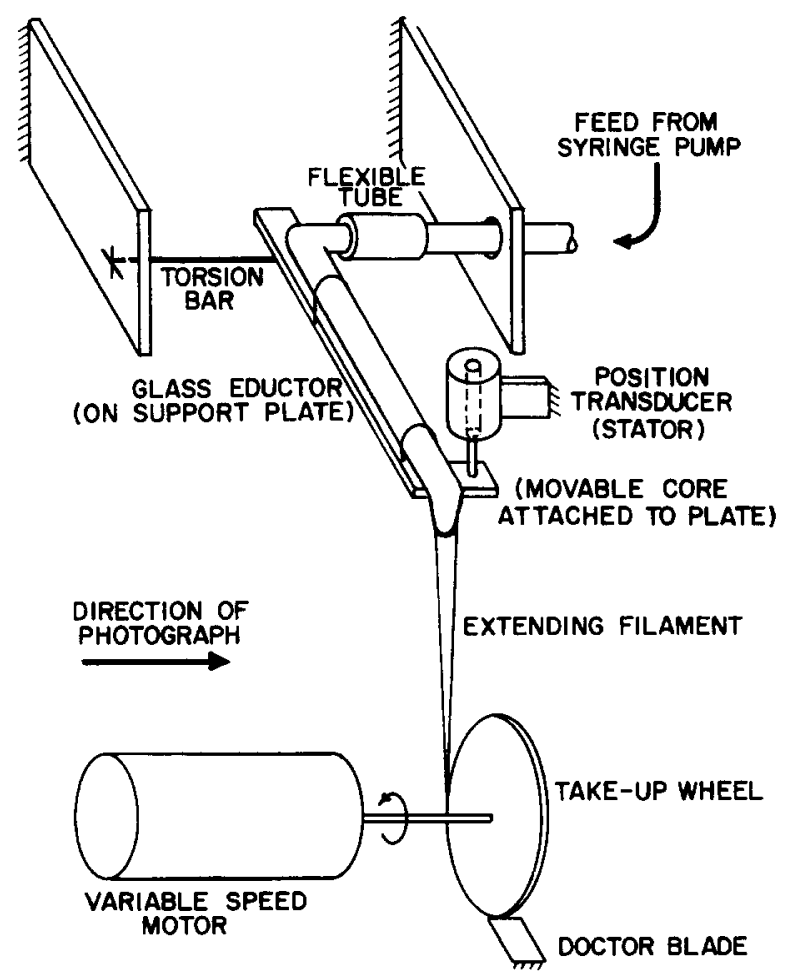

Figure 2. Schematic diagram of spinning apparatus used in this study. 
to determine experimentally whether this was a significant variable. With the fluids studied, no effects of diameter could be detected. Calculations (Weinberger 1970) showed that the temperature rise from viscous dissipation of energy in the spinning threadline could be neglected.

The principal experimental variables were:

length of the fluid filament;

wind-up speed;

volumetric flow rate;

die or nozzle diameter.

Overall fluid filament lengths were varied from 60 to $170 \mathrm{~mm}$ and rates of extension were varied from 0.4 to $10 \mathrm{sec}^{-1}$.

Filament diameters, measured from photographs of the threadline, and measured efflux rates provided local velocity values. The assumption of a flat velocity profile was not verified directly in the present work, since axial velocities at various radial positions were not measured. However, the speed of small bits of saw-dust placed on the surface of the filaments were measured and found to agree, within the 10 per cent experimental accuracy of the saw-dust measurement, with those speeds calculated from the diameter measurements (Weinberger 1970). (Unfortunately, this is not a very stringent test for the absence of radial gradients.)

Measurements of the tensile force completed the information necessary to specify the rheology of the spinning motion. The tensile force, as a function of position, was determined from the measurement of the overall tensile force at the nozzle, essentially by means of [2.10]. The integration was accomplished stepwise, using as steps the actual intervals between diameter measurement, intervals ranging from 2 to $8 \mathrm{~mm}$. Typically, each filament was divided into 20 increments, so that each run yielded 20 pairs of numbers, each pair consisting of the local tensile stress and the local extension rate.

At high rates of extension the tensile stress measurement was relatively more accurate than the extension-rate measurement. The reason for this was that the higher extension rates were achieved in the region where the filament was thinner and where a small change in diameter could correspond to a high rate of extension. Consequently, the percentage uncertainty of most of the extension rate values reported here was estimated to be 30 per cent, while that of the tensile stress was roughly 5 per cent. (Tensile-stress data from the lower region of the filament during nearly free-fall conditions were much less accurate, however, and these data were not included here but are available in Weinberger 1970.)

It should be emphasized in this context, that we employed finite-difference differentiation of diameter data, without any attempts to smooth data, by previously curve fitting or other such devices. In this sense, the interpretation of data was relatively direct and free of analytical artifact. In this regard, we feel that there has perhaps not been enough attention given in the literature on spinning to the very difficult problem of obtaining accurate filament diameter measurements.

As for filament stability in the present work, oscillatory variations in the filament diameter and the tensile stress could occasionally be observed. The onset of these oscil- 
lations depended on the nozzle diameter and the flow rate and thus, could be associated with the physical dimensions of the apparatus and not merely the rheological response of the material. No attempt was made to study these oscillations, and measurements were made only under experimental conditions where the oscillatory behavior did not appear to be significant. We should also note that no elaborate precautions were taken to control the temperature of the spinning filament, but the ambient laboratory air temperature was nominally controlled at $25( \pm 0.2)^{\circ} \mathrm{C}$.

\subsection{Results of shear tests on polymer solutions}

The shear viscosity of the silicone oil varied less than 5 per cent, as the shear rate was increased from $10^{-2}$ to $20 \mathrm{sec}^{-1}$. Moreover, the shear stress decayed rapidly upon cessation of shear (half-lives of less than $0.01 \mathrm{sec}$ ) over the same range of shear rates. The constancy of viscosity and rapidity of stress relaxation satisfied us that the oil could be considered Newtonian at the shear rates of interest.

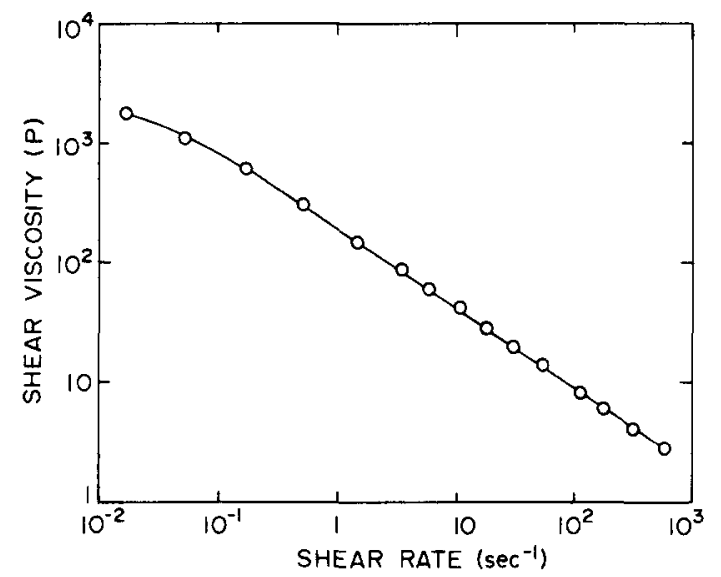

Figure 3. Apparent viscosity vs shear rate for Separan solution.

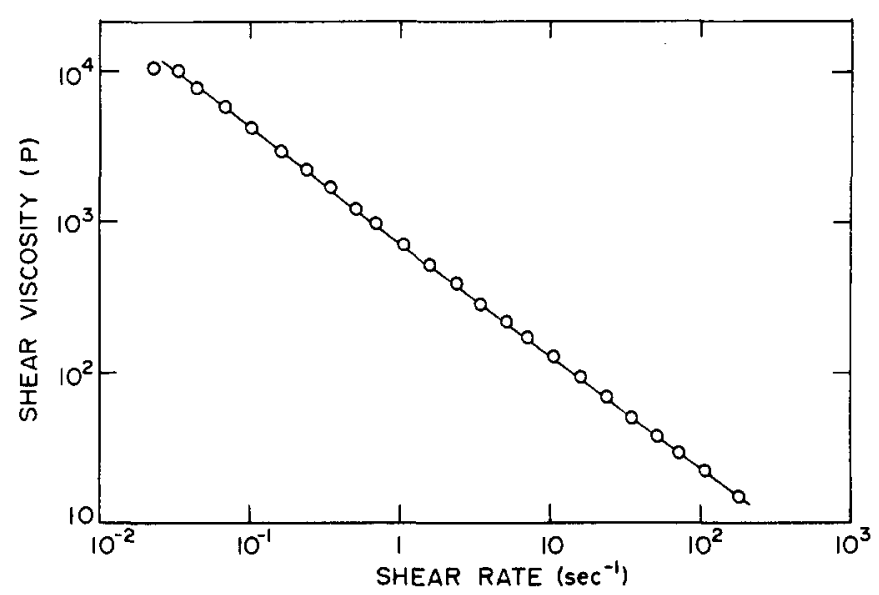

Figure 4. Apparent viscosity vs shear rate for Polyox solution. 
The Separan and Polyox solutions exhibited the usual marked non-Newtonian behavior, particularly with regard to shear-thinning and gradual stress-relaxation. Their shear viscosities exhibited typical power-law behavior, figures 3 and 4 , and the power-law exponents for the two fluids were similar: -0.67 for Separan and -0.75 for Polyox.

The elasticity of the Separan and Polyox solutions was also evident from the shearrelaxation tests. Starting from various shear rates, the stress decayed gradually upon cessation of shear. Although the stress-decay curves were not quite exponential with time, an approximate measure of the relaxation time was obtained by noting the time required for the shear stress to decay to $1 / e$ of its steady value. This time period amounted to nearly

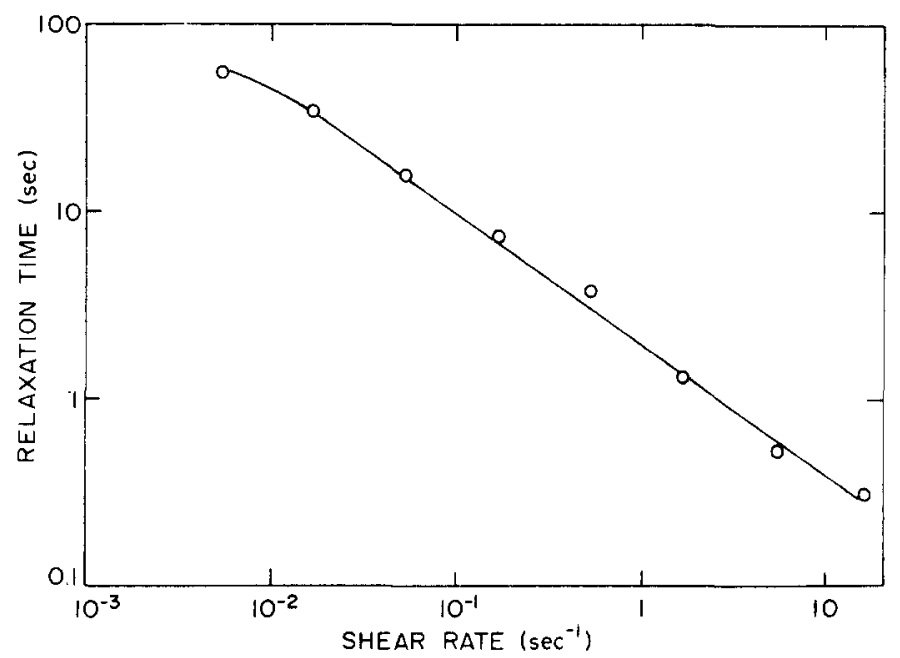

Figure 5. Apparent relaxation time (based on 1/e decrement of shear stress after cessation of steady shear) vs shear rate for Separan solution.

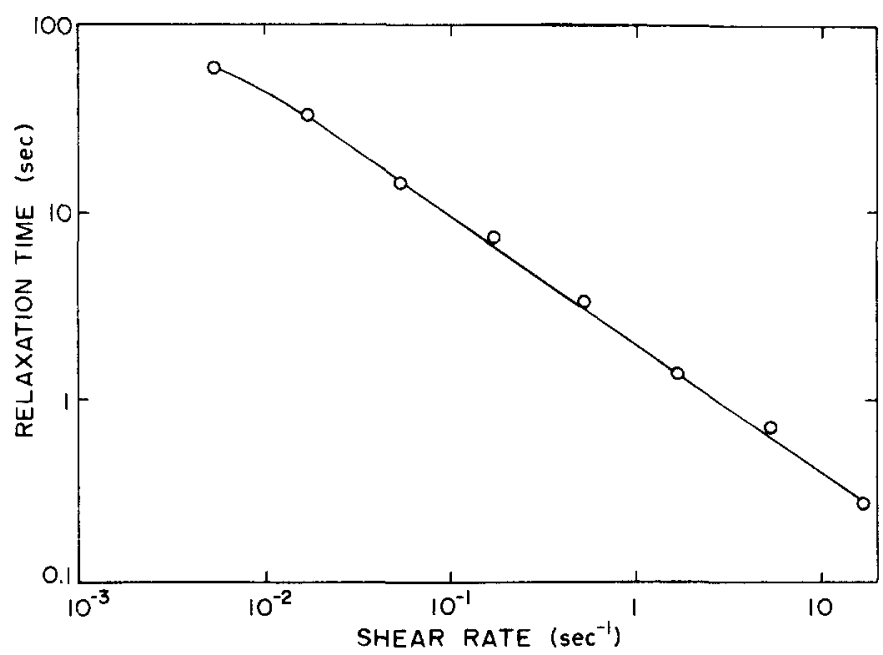

Figure 6. Apparent relaxation time (based on $1 /$ e decrement of shear stress after cessation of steady shear) vs shear rate for Polyox solution. 
$70 \mathrm{sec}$ for both fluids at low shear rates, figures 5 and 6 and, as the shear rate increased, decreased to only $0.3 \mathrm{sec}$ at a shear rate of $10 \mathrm{sec}^{-1}$. By coincidence, the two fluids were quantitatively similar in their relaxation behavior. The similarity in shear properties (relaxation time and power-law exponent) will become more significant when we compare the solutions' behavior in extensional flow.

The shear viscosity of the fluid suspensions was increased only slightly by the presence of the particles ( 13 per cent) for the silicone oil suspension, and ( 8 per cent) for the Indopol suspension (table 2). The suspension viscosities decreased by less than 3 per cent as the shear rate increased from 1 to $10 \mathrm{sec}^{-1}$.

\section{RESULTS AND DISCUSSION OF EXTENSIONAL TESTS}

\subsection{Newtonian fluid}

Experimental tensile stress values for the silicone oil are presented in figure $7{ }^{*}$ The slope of unity on the logarithmic plot shows the tensile stress proportional to the extension rate, a result expected for a Newtonian fluid. Moreover, the observed values for the tensile stress superpose upon the line predicted from the measured shear viscosity. Most of the data fell within 20 per cent of the predicted tensile stress. Such agreement with theory served to verify the capabilities of the experimental apparatus.

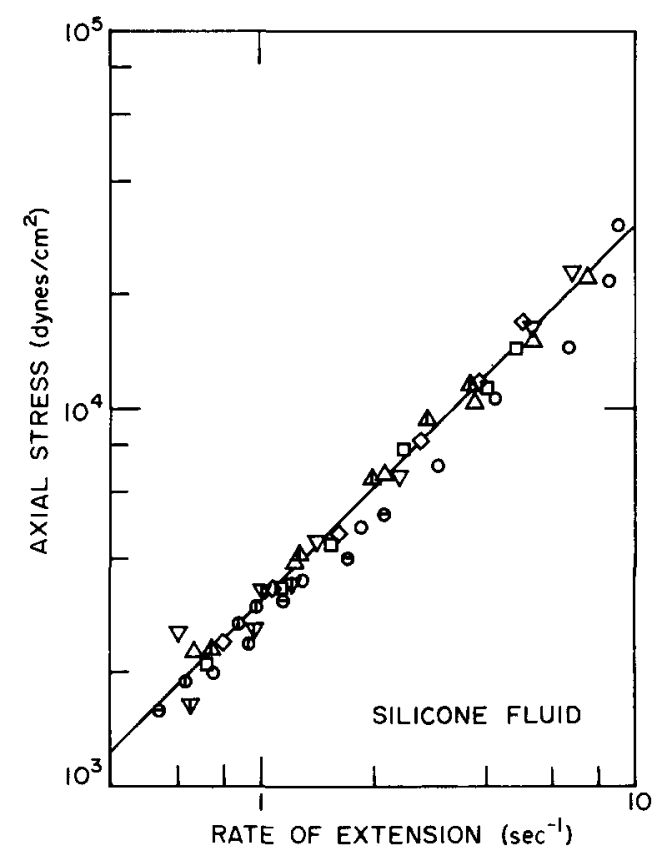

Figure 7. Comparison of experimentally observed tensile stresses with those predicted from the shear viscosity of the Silicone fluid (solid line).

\footnotetext{
* Figure 7 shows slightly better agreement with theory than a corresponding plot, figure (4.16) of Weinberger (1970): the latter involves a small but systematical computational error.
} 


\subsection{Polymer fluids}

Figures 8 and 9 show the tensile stress-extension rate curves found for the viscoelastic fluids. The striking feature of each plot is the nearly straight-line relationship. This indicates a power-law increase of spinning viscosity with extension rate, in distinct contrast to the decrease of shear viscosity with increasing rate of shear.

Since we know of no other work on polymer solutions which relates spinning viscosity directly to extension rate, we are not able to comment on the empirical soundness of the observed power-law dependence, other than to note simply that the representation sufficed here over a broad range of deformation rates, in extension as well as shear. The more striking and significant feature was the opposite type of dependence of viscosity upon deformation rate in spinning and in shear, as summarized schematically in figure. 10 and numerically in table 1 . This illustrates the importance of the mode of deformation to the non-linear dependence of stress on deformation rate, although this observation suffers somewhat because of the comparison of rheological behavior for time-invariant kinematics (steady shear) with that for time-varying kinematics (spinning). However, recalling from Section 2.2 that the Trouton viscosity is likely to be greater than the spinning viscosity, we are inclined to speculate that, for systems with an increasing spinning viscosity, the difference in rheological behavior is likely to be even greater between the cases of truly steady extension and steady shear.

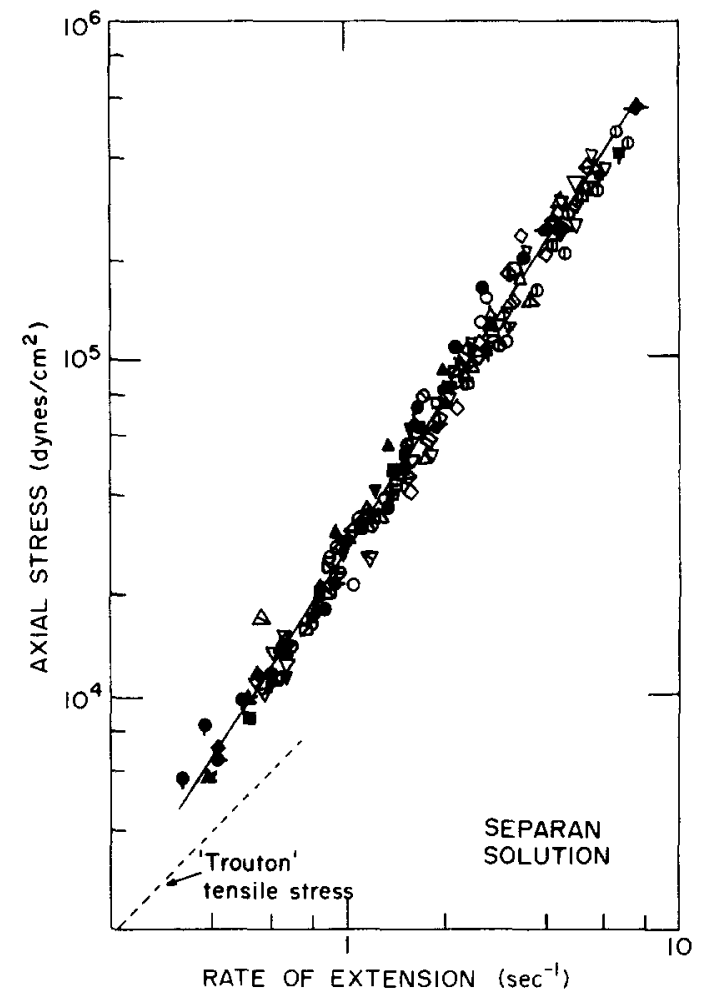

Figure 8. Local stress $\tau$ vs strain rate $\dot{\varepsilon}$ for spinning of Separan solution. 


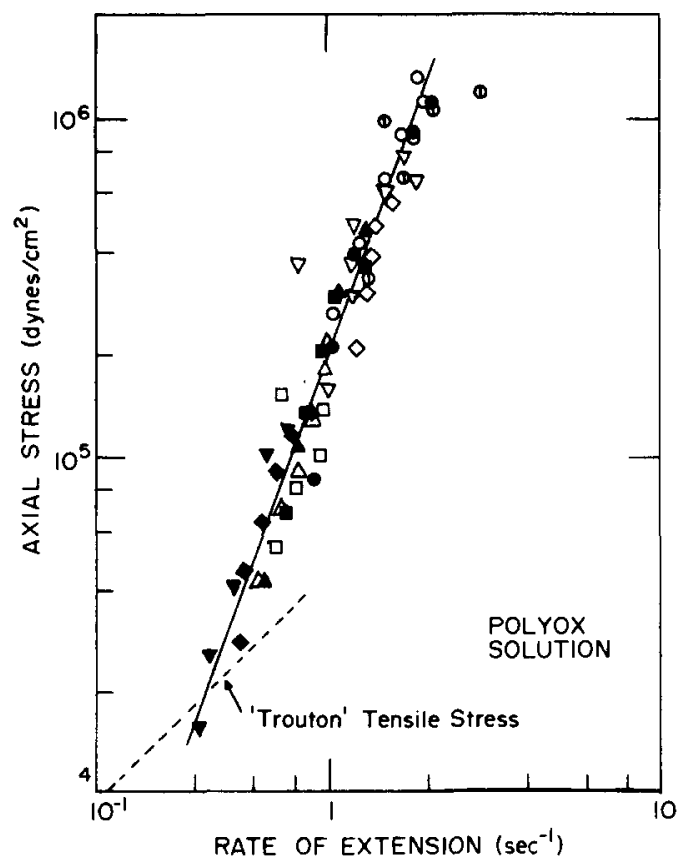

Figure 9. Local stress $\tau$ vs strain rate $\dot{\varepsilon}$ for spinning of Polyox solution.
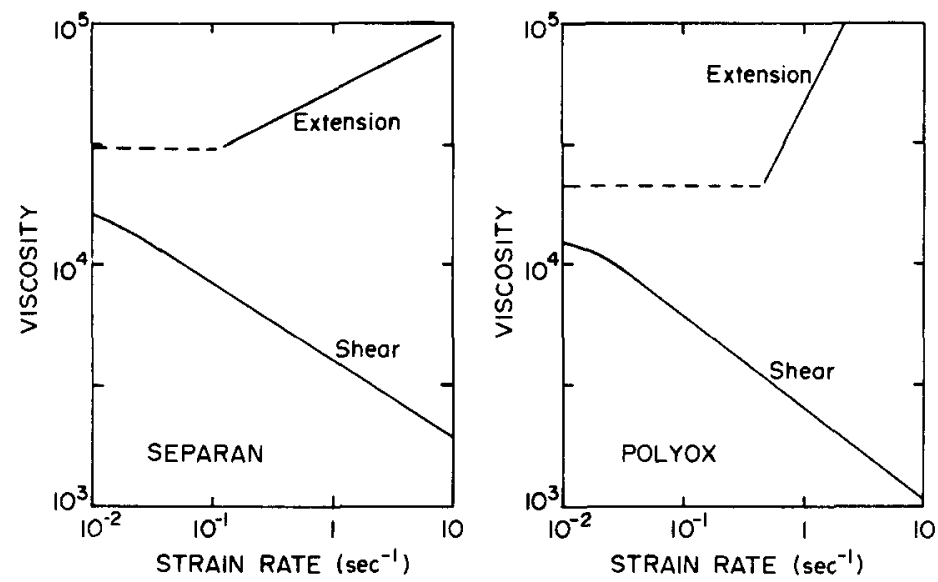

Figure 10. Comparison of observed apparent viscosity vs strain rate (shear rate or extension rate) for Separan and Polyox solutions in shear and extension (spinning). The broken lines -..-- for extension represent the "Trouton" asymptotes, based on the "zero-shear" viscosities of the solutions.

Table 1. Summary of observed, power-law dependence of apparent viscosities (poises) of polymer solutions on strain rates $\left(\mathrm{sec}^{-1}\right)$.

\begin{tabular}{lllll}
\hline Solution & \multicolumn{1}{c}{$\eta_{\text {shear }}$} & Range of $\dot{\gamma}$ & \multicolumn{1}{c}{$\eta_{\text {spin }}$} & Range of $\dot{\varepsilon}$ \\
\hline Separan & $1.94 \times 10^{2}(\dot{\gamma})^{-0.67}$ & $0.1-1000$ & $2.82 \times 10^{4}(\dot{\varepsilon})^{0.485}$ & $0.4-8$ \\
Polyox & $7.0 \times 10^{2}(\dot{\gamma})^{-0.75}$ & $0.03-300$ & $2.10 \times 10^{5}(\dot{\varepsilon})^{1.724}$ & $0.4-2$ \\
\hline
\end{tabular}


In a spinning filament the extension rate usually increases with distance from the nozzle. Therefore, on figures 8 and 9, points higher on the curve correspond to positions farther downstream on the filament. Each symbol refers to different experimental conditionsdifferent lengths, flow rates, wind-up speeds, and nozzle diameters. The single fit of all the data indicates, we feel, that none of these variables is significant. Those data for draw-ratios (velocity/nozzle efflux velocity) less than two correspond generally to the velocity-rearrangement region near the nozzle and thus were excluded from the plots.*

Most of our experiments on the polymer solutions resulted in a nearly constant-force spinning, as defined in Section 2.2 above. Thus, after corrections for inertia, gravity and surface tension, the spinning force $(\tau A)$ was at least 80 per cent as large at the take-up disk as that at the nozzle, in roughly 80 per cent of the tests, and at least 90 per cent as large in 60 per cent of the tests.

If we assume these fluids exhibit fading memory, whereby they become Newtonian at low rates of deformation, we can estimate the limiting Trouton viscosity (thrice the zeroshear viscosity) and the corresponding Newtonian asymptote, as displayed at the lower left-hand corner of each plot. Although the data certainly do not indicate strict Newtonian behavior at the lower extension rates, they do exhibit the expected numerical magnitudes.

It is interesting to compare the behavior of the one viscoelastic fluid against the other. It may be recalled that the elastic behavior as determined from shear stress-relaxation experiments, was roughly the same for the two fluids; their relaxation times, at equivalent shear rates, were within 30 per cent of each other. Furthermore, although the apparent shear viscosity of the Polyox solution was from three to five times that of the Separan solution, the power-law dependence of the shear viscosity upon the shear rate was roughly similar (the shear viscosity decreased slightly faster with the Polyox solution, as the power -0.75 of shear rate vs -0.67 for the Separan). Except for the difference in the absolute value of viscosity, then, the two fluids exhibited nearly identical shear behavior $t$ However, this quantitative similarity in behavior did not carry over to the spinning experiments. Here the "spinning viscosity" of the Separan solution increased with the 0.49 power of extension rate whereas that of the Polyox increased with the 1.72 power. This difference in behavior serves perhaps to emphasize the insufficiency of simple experiments on shear as a basis for predicting rheological response in spinning.

Because of the fundamentally different behavior in shear and extension, one can not expect fluid models which were developed solely on the basis of shear tests, to provide reliable predictions of spinning behavior. Thus, for example, if one employs the rheological equation proposed by Spriggs (1965) with constants obtained for the Separan solution by

\footnotetext{
* The data presented here represent all but two runs (No's. 47-30 and 47-32 of Weinberger 1970) from a total of 37. The two excluded runs, which as pointed out to us by Kanel (1970) show some departure from the other data of figure 8 , both correspond to small strain rates and tensile forces and, a co-incidentally small camera magnification. The data from other runs (No's. 47-21, 53-1, 53-10 and 54-32, ibid.), corresponding to roughly the same conditions but with larger camera magnification, are included in figure 8 . At any rate, all the raw data are available elsewhere (Weinberger 1970).
}

+ Since the normal stress viscometric functions were not measured, a complete characterization of the fluids' rheology in shear was not obtained. 
Huppler, Ashare \& Holmes (1967) the solution is predicted to have an infinite spinning viscosity at an extension rate of $5.7 \times 10^{-3} \mathrm{sec}^{-1}$. This is approximately two decades lower than the extension rate for the inception of non-linear behavior, as observed in this work. Other existing models could also be considered, but none of the simpler ones was found to provide an adequate description of the present experimental results for both shear and extension (Weinberger 1970).

We recall that spinning motion experiments with aqueous polyacrylamide solutions were also performed by Zidan (1969). Qualitatively, he observed different relationships between tensile stress and extension rate as the spinning conditions were changed, whereas we observed a unique relationship. A quantitative comparison of results cannot be made, however, since Zidan's experiments were different in the following respects:

higher molecular weight polymer;

higher extension rates;

a constant or decreasing extension rate with increasing distance from the nozzle.

The last of these may indicate that constant tensile force conditions were not realized in his experiments for had they been, one would infer a very implausible decrease of tensile stress with extension rate. The lack of constant tensile force could in turn account for the lack of a unique (or monogenic) deformation history in his experiments, which prevented Zidan from obtaining a unique material function for the polyacrylamide solution.

\subsection{Particle suspensions}

The suspended rod-shaped particles exerted a powerful effect on the extensional rheology of the fluid suspensions. At a concentration of only 1.3 volumetric-per cent, the spinning viscosity was increased approximately 10 -fold over that of the suspending fluid.

In figures 11 and 12 the tensile stress is plotted versus the extension rate.* The two principal features of both plots, as summarized in table 2, are:

(1) a constant spinning viscosity (slope of unity); and

(2) a nearly ten-fold increase in tensile stress over that of the suspending fluid alone.

The constant viscosity was manifest shortly after the suspension exits the nozzle; the spinning viscosity reached a constant value after achieving draw ratios of only 2 to 2.3 .

Table 2. Summary of observed viscosities (poises) of suspending fluids and fluid suspensions.

\begin{tabular}{lcccc}
\hline & \multicolumn{2}{c}{$\eta_{\text {shear }}$} & & \\
Fluid & Without particles & 1.3 vol per cent particles & Without particles & 1.3 vol per cent particles \\
\hline Silicone & 1000 & 1130 & 3000 & 29,000 \\
Indopol & 205 & 235 & $(615) \dagger$ & 5400 \\
\hline
\end{tabular}

+ Calculated as $3 \eta_{\text {shear }}$.

* The scatter in data is much greater for the suspensions than for the polymer solutions. Since the suspension possessed a less smooth filament surface, the extension rate measurement was somewhat less precise. 


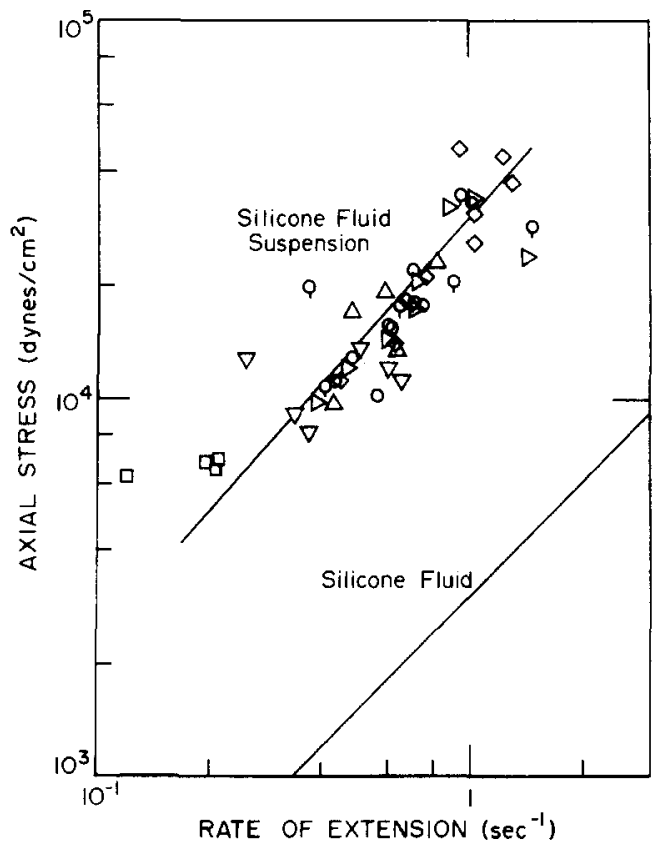

Figure 11. Local stress $\tau$ vs strain rate $\dot{\varepsilon}$ for glass-fiber suspension in Silicone fluid. The lower solid line is the theoretical stress for the pure fluid, based on measured shear viscosity.

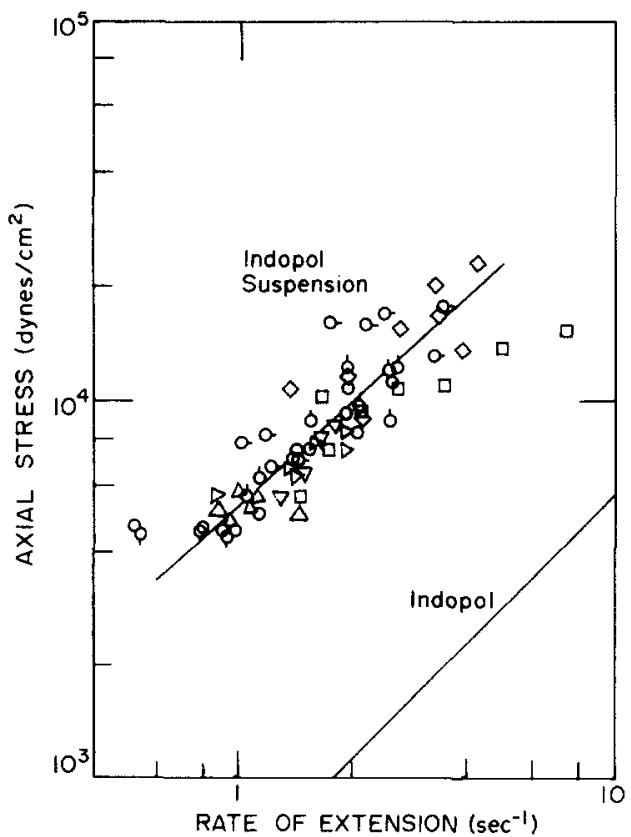

Figure 12. Local stress $\tau$ vs strain rate $\dot{\varepsilon}$ for glass-fiber suspension in Indopol. The lower solid line is the theoretical stress for the pure fluid, based on measured shear viscosity. 
This tended to indicate the efficacy of the extensional motion for quickly aligning the particles with the flow. Moreover, additional extensional strain did not appear to further align the particles, since the apparent viscosity remained constant over the remainder of the filament.

\subsection{Implications for microrheology}

For the particle suspensions studied here, the 10 -fold increase in tensile stress over that of the suspending fluid can be compared to the roughly 8 per cent increase in shear stress. Hence, the presence of the particles affects the suspension rheology far more in extensional flow than in shearing flow. This is not surprising if one realizes that a high degree of orientation of the elongated particles along the major axis of extension should result in a high tensile stress.

Theoretically, this effect can be anticipated from a microrheological analysis according to a classical hydrodynamic treatment of suspensions of rod-shaped particles in a viscous fluid. Recently, Batchelor (1971) has given a fairly comprehensive analysis of the extensional flow behavior of elongated particle suspensions in the limits of dilute-suspension and closeparticles conditions, and has given a formula for the tensile stress increase $\tau_{\boldsymbol{P}}$ due to the particles. He has already noted that the suspensions used in our work satisfy neither the dilute-suspension nor the close-particle description, but fall between the two. He has also proposed the following:

$$
\tau_{P}=\left[\frac{(4 \pi / 9) N l^{3}}{\ln \left(2 l / R_{0}\right)-\ln (1+2 l / h)-3 / 2}\right] 3 \mu \dot{\varepsilon},
$$

where $\mu$ is the viscosity of the (Newtonian) suspending fluid, $N$ is the number of particles per unit volume, $2 l$ and $R_{0}$ are the particle length and radius, respectively, and

$$
h=[2 N]^{-1 / 2}
$$

is a measure of the distance between particles. Equation [4.1] has the appropriate asymptotic forms, approaching either the dilute-suspension or close-particle formula as the ratio $h / l$ becomes large or small, respectively. For the suspensions of the present work, one calculates by [4.1], a tensile stress 8.4 times that of the suspending fiuid, in reasonable agreement with the observed factors of 9 to 10 for total stress (figures 11 and 12 and table 2). The success of Batchelor's equation with these two suspensions leads us to expect similar success in experiments with varying particle concentration and length to width ratio. Unfortunately, we did not examine experimentally these other variables in the present work.

It is interesting to observe that the extensional flow behavior of the polymer solutions and the fluid suspensions can be linked qualitatively. Each system exhibited high tensile stresses compared to the shearing stresses at the same deformation rates. For the polymer solutions, this could be caused by an orientation of the coiled molecules into elongated conformations, whereas for the suspensions it is almost certainly due to alignment of the rod-shaped particles parallel to the axis of extension. At any rate, both physical descriptions correspond to a situation where the specific contribution of the molecule or particle to the stress-state is greater in extension than in shear. 
The search for such qualitative similarity between suspension and solution was actually one of the objectives of the present work. On the basis of this positive finding, an attempt was made to establish a degree of quantitative similarity. The dilute suspension form of [4.1] was applied to the polymer solutions, with particle parameters estimated roughly from bond angles and molecular dimensions for fully extended chains. It is rather surprising to find that for both polymer solutions the calculated stresses agree to within 20 per cent of those observed at an arbitrarily chosen extension rate of approximately $1 \mathrm{sec}^{-1}$ (Weinberger 1970).

In view of the observed non-linear behavior of the polymer solutions and the obvious limitations on the rigid-particle suspension model, no attempts were made to further refine the above calculation.

\section{CONCLUSIONS}

Our measurements on spinning filaments of polymer solutions and elongated-particle suspensions lend much support to the notion that orientation effects in extensional motions should lead to much larger stress contributions, from elongated macromolecules in solution or particles in suspension, than for simple shearing flows.

Moreover, we have been able to correlate quantitatively stress versus strain-rate for essentially all our spinning experiments on these fluids, in contrast to the previous work of Zidan (1969) on similar polymer solutions. This may well be due to a particularly reproducible history in the spinning experiments reported here, since most of our data correspond approximately to constant-force spinning conditions. At any rate, it appears to be possible to eliminate the influence of other variables such as eductor diameter or other die effects.

Experiments by one of the authors (J. D. G.) are now in progress to investigate the dynamical optical properties of polymer solutions in spinning, in order to provide further evidence of molecular orientation. The present findings suggest that some refinements on the elongated particle model might provide a fairly accurate description of molecular configuration and stress contributions in extension flows, at least for solutions of polymer in Newtonian solvents. If so, this type of flow could offer some interesting possibilities for investigation of the morphological features and optical properties of individual macromolecules in a well-defined, perhaps near fully-extended state of orientation. In this regard, there is every motivation for attempting higher rates of strain than those obtained here.

In the interpretation of our experiments, we have tried here to suggest some criteria for the dynamical conditions necessary to obtaining reproducible histories $\dagger$ and hence, rheological tests in the spinning experiment. As pointed out in that connection, it would be interesting and perhaps practically useful to consider this question in more detail.

Acknowledgement - The authors are indebted to Dr. F. A. Kanel, of the University of Delaware, Department of Chemical Engineering, for private discussions with one of us (C. B. W.) on the interpretation of the spinning experiment. The notion of "monogenic" extensions developed here in Section 2.1 represents, to a degree, an extension and elaboration on an idea which, we understand, is to be found in his recent Doctoral Dissertation (Kanel 1972).

\footnotetext{
+ See the Acknowledgement.
} 


\section{REFERENCES}

BAtChelor, G. K. 1971 The stress generated in a non-dilute suspension of elongated particles by pure straining motion. J. Fluid Mech. 46, 813-829.

Brown, D. R. (Appendix by G. I. Taylor) 1961 A study of the behavior of a thin sheet of moving liquid. J. Fluid Mech. 10, 297-305.

Clarke, N. S. 1968 Two dimensional flow under gravity in a jet of viscous liquid. J. Fluid Mech. 31, 481-500.

Cogswell, F. M. 1972 Measuring the extensional rheology of polymer melts. Trans. Soc. Rheol. 16, 383-403.

Coleman, B. D. \& Noll, W. 1961 Foundations of linear visco-elasticity. Revs. Mod. Phys. 33, 239-249.

Coleman, B. D. \& Noll, W. 1962 Steady extension of incompressible simple fluids. Phys. Fluids 5, 840-843.

Dealy, J. M. 1971 Extensional flow of non-Newtonian fluids-A review. Polymer Engng Sci. 11, 433-445.

Huppler, J. D., AshaRe, E. \& Holmes, L.'A. 1967 Rheological properties of three solutions -Part I. Trans. Soc. Rheol. 11, 159-180.

Kanel, F. A. 1970 Private communications to C. B. Weinberger (cf. Kanel, F. A. 1972 The extension of viscoelastic materials, Ph.D. Thesis. University of Delaware).

Matovich, M. A. \& Pearson, J. R. A. 1969 Spinning a molten threadline. I. \& E.C. Fund. 8, 512-520.

MEISSNER, J. 1972 Development of a universal extensional rheometer for the uniaxial extension of polymer melts. Trans. Soc. Rheol. 16, 405-420.

Metzner, A. B. \& Metzner, A. P. 1970 Stress levels in rapid extensional flows of polymer fluids. Rheo. Acta 9, 174-181.

NitschmanN, H. \& SChrade, J. 1948 Uber das Fadenzeihvermogen bei Flussigkeiten als Viskostatsanomalie. Helv. Chim. Acta 31, 297-319.

NoLl, W. 1958 A mathematical theory of the mechanical behavior of continuous media. Arch. Ratio. Mech. Analysis 2, 197-226.

PIPKIN, A. C. 1972 Lectures on Viscoelasticity Theory, Chapter VIII, p. 131. Springer.

Slattery, J. C. 1966 Spinning of a Noll simple fluid. A.I.Ch.E. J. 12, 456-460.

Spriggs, T. W. 1965 A four-constant model for viscoelastic fluids. Chem. Engng Sci. 20, 931-940.

TANNER, R. I. 1968 Comparative studies of simple viscoelastic theories. Trans. Soc. Rheol. 12, 155-182.

Trouton, F. T. 1906 On the coefficient of viscous traction and its relation to that of viscosity. Proc. Roy. Soc., Lond. A77, 426-440.

Truesdell, C. 1966 The Elements of Continuum Mechanics, Lecture 7, p. 65. Springer. WeInBERGER, C. B. 1970 Extensional flow behavior of non-Newtonian fluids, Ph.D. Dissertation. University of Michigan.

ZIA BICKI, A. 1967 Man Made Fibers-Science and Technology, Vol. 1 (Eds., Mark, H. F., Atlas, S. M. \& Cernia, E. Wiley-Interscience.

Zidan, M. 1969 Zur Rheologie des Spinn Prozesses. Rheo. Acta 8, 89-123. 
Sommaire -..-Le filé mécanique de filaments fluides a été utilisé pour la génération d'un écoulement extensionel dans lequel des mesures rhéologiques ont été obtenues pour un fluide Newtonien, deux solutions aqueuses de polymères, et deux suspensions en fluide de particules en forme de bâtonnets. La contrainte en traction a été déterminée en mesurant les forces de traction du filament fluide alors que la cinématique a été déterminée à partir de mesures photographiques du profilé du filament et de la supposition que le profil de vélocité est plat. Les contraintes de traction mesurées pour le fluide Newtonien étaient semblables aux contraintes prévues, confirmant ainsi la validité de la technique expérimentale.

Le comportement mécanique de chaque solution de polymères a pu être représentée comme contrainte en fonction du taux d'extension. La "viscosité de file" apparente augmentait en même temps que le taux d'extension, en contraste au comportement en cisaillement dans un écoulement viscométrique. Pour les suspensions en fluide, la présence de particules en forme de bâtonnets augmente la viscosite apparente bien d'advantage dans l'ècoulement extensionel qu'en cisaillement. Les tractions calculées d'une formule théorique pour les suspensions proposée par Batchelor ont montré un bon accord avec l'expérience. Quelques critères généraux pour l'interprétation de l'expérience de filé sont proposés, et quelques implications microrhéologiques des découvertes presentes sont discutées.

Auszug --Es wurde ein mechanischer Spinnung von Flüssigkeitsfäden zur Schaffung eines Ausstreckungsflusses benutzt, in welchem rheologische Messungen für eine Newton'sche Flüssigkeit, zwei wäßrige Polymerlösungen und zwei Flüssigkeitssuspensionen von stabförmigen Partikeln erhalten wurden. Die Zugfestigkeit wurde durch Messung der Zugkraft des Flüssigkeitsfadens bestimmt. während die Kinematik aus der photographischen Messung des Fadenprofils und unter der Voraussetzung eines flachen Geschwindigkeitsprofils bestimmt wurden. Die gemessenen Zugfestigkeiten für die Newton'sche Flüssigkeit waren den vorausgesagten Spannungen angepaßt. und die Gültigkeit des experimentellen Verfahrens bestätigte sich daher.

Das Spinnungverhalten jeder Polymerlösung konnte als Spannungsgrad versus Ausstreckungsgrad in Verbindung gebracht werden. Die scheinbare "Dehnviskosität" stieg mit Vergrößerung des Ausstreckungsgrades, im Gegensatz zu der Verdünnung des Scherverhaltens im viskometrischen Fluß. Bei Flüssigkeitssuspensionen stieg die scheinbare Viskosität bei Vorhandensein von stabförmigen Partikeln weit mehr im Ausstreckungsfluß als im Scherfluß. Aus theoretischen Formeln für Suspensionen nach Vorschlag von Batchelor errechnete Zugfestigkeiten stimmten ziemlich gut mit dem Experiment überein. Es werden einige allgemeine Kriterien zur Ausdeutung der Spinnprozesse vorgeschlagen, und es werden einige mikrorheologische Begleiterscheinungen der vorhandenen Ergebnisse besprochen.

Резюме - Механическим вращением струй жидкости генерировали растяжимый поток, при чем гроводились реологические измерения ньютоновской текучей среды, использовались два водных раствора полимера, и две жидкие суспензии палочкообразных частиц. Растягивающее напряжение определялось измерением силы растяжения струи текучей среды, а кинематика определялась по фотографическому измерению профиля струи и предпожением о плоской зпюре скоростей. Измеренные растягивающие напряжения иьютоновской текучей среды соответствовали предсказанным напряжениям, что подтвердило обоснованность експериментальной техники.

Вращательное поведение обоих полимерных растворов можно взаимно связать как корреляция напряжение: растяжение. Очевидная вязкость вращения повышается с ускорением растяжения, в противоположность разреженному потоку, подверженному касательному напряжению в вискозиметре. Что касается жидких суспензий. присутствие палочкообразных частиц повышает кажущуюся вязкость на много больще в растяжимом потоке. чем в разреженном потоке. Растягивающее напряжение рассчитанное по теоретической формуле для суспензий по теореме Батчелора довольно точно соответсвует зксперименту. Предлагается общий критерий для пояснения зксперимента вращения и обсуждаются некоторые микрореологические следствия настояших зкспериментальных ланных 